\title{
Serum Endocan, Neuron-Specific Enolase and Ischemia-Modified Albumin Levels in Patients with Symptomatic Polycytemia who underwent Partial Blood Exchange Transfusion
}

\author{
Erbu Yarci ${ }^{1}$, Ufuk Cakir $^{1}$, Omer Ertekin ${ }^{1}$, Utku Serkant $^{2}$, Cuneyt Tayman' ${ }^{1}$ \\ ${ }^{1}$ Zekai Tahir Burak Women's Health Education and Research Hospital, Neonatology, Ankara, Turkey. \\ ${ }^{2}$ Golbasi Government Hospital, Biochemistry, Ankara, Turkey.
}

\begin{abstract}
Background and Aims: The purpose of this study was to evaluate the levels of serum Endocan, Neuron specific Enolase (NSE), and Ischemia-Modified Albumin (IMA) levels in term newborn with polycytemia who underwent partial blood exchange transfusion (PET).
\end{abstract}

\begin{abstract}
Method: The aim of this study was to compare term newborn babies born in our hospital between December 1, 2015 and December 1,2017 with term newborns with symptomatic polycytemia and healthy term newborns (control group). Blood samples for serum Endocan, NSE and IMA levels were taken at 24th and 72th hours after PET in patients in polycytemia group. In the control group blood samples were taken for serum Endocan, NSE and IMA levels at 24 hours after birth.

Results: 38 patients with polycytemia and 38 control patients were included in the study. IMA, Endocan, NSE values were significantly higher in the polycytemic group than the contro group $(\mathrm{p}<0.05)$. Endocan and IMA values were significantly higher than control group but not completely normal $(\mathrm{p}<0.05)$ when compared with control group and PET patients. When the control group and PET patients were compared, it was seen than the NSE values decreased to the control group values and there was no difference $(p>0.05)$.
\end{abstract}

Table 1. Demographic and clinical characteristics of the groups

\begin{tabular}{|l|c|c|c|}
\hline Variables & $\begin{array}{l}\text { Control group } \\
(\mathbf{n = 3 8}) \text { mean } \pm \text { SD } \\
\text { median(IQR) } \\
\text { min-max n/\% }\end{array}$ & $\begin{array}{l}\text { Polycythemia group } \\
(\mathbf{N = 3 8}) \text { mean } \pm \text { SD } \\
\text { median(IQR) } \\
\text { min-max n/\% }\end{array}$ & p* \\
\hline Maternal age & $28.3 \pm 3.6$ & $28.0 \pm 4.8$ & 0.685 \\
\hline (year) & $(19-35)$ & $(16-30)$ & \\
\hline Vaginal delivery & & & \\
\hline Gestational age & $16 / 42.1 \%$ & $15 / 39.5 \%$ & 0.430 \\
\hline (week) & $38.7 \pm 0.6$ & $38.5 \pm 0.8$ & 0.21 \\
\hline Birth weight(gr) & $3268.8 \pm 435.8$ & $3352.2 \pm 493.5$ & 0.985 \\
\hline APGAR 1.min & $7(1)$ & $7(2)$ & 0.235 \\
\hline APGAR 5. Min & $9(1)$ & $9(2)$ & 0.524 \\
\hline Sex & & & \\
\hline \multicolumn{1}{|c|}{ Male } & $17 / 44.7 \%$ & $18 / 47.4 \%$ & 0.712 \\
\hline
\end{tabular}

$* \mathrm{p}<0.05$ statistically significant
Conclusion: The results of our study suggest that serum Endocan and IMA levels may be used as biomarkers in the demonstration of endothelial injury/disfunction and tissue hypoxia in patients with PET. In the study group, there was no difference between the control group and post-PET in NSE levels being associateed with the absence of neurological symptoms in the polycytemia group.

Table 2. Comparison of Endocan, IMA, and NSE levels control group and polycytemia group

\begin{tabular}{|l|l|l|l|c|}
\hline Variables & Control & Before PET & After PET & $* \mathbf{p}$ \\
\hline IMA & $0.601 \pm 0.095$ & $1.32 \pm 0.34$ & $0.656 \pm 0.070$ & $0.000^{\mathrm{a}, \mathrm{b}}$ \\
\hline ENDOCAN & $378.85 \pm 95.90$ & $1073.454 \pm 64$ & $510.93 \pm 228.6$ & $0.000^{\mathrm{d}, \mathrm{e}}$ \\
\hline NSE & $26.91 \pm 7.12$ & $44.7 \pm 4.3$ & $28.98 \pm 6.5$ & $0.000^{\mathrm{g}, \mathrm{h}}$ \\
\hline & & & & \\
\end{tabular}

$* p<0.05$ Statistically significant

a: Comparison of IMA levels between control group and study group before PET

b: Comparison of IMA levels in the study group before and after PET

c: Comparison of IMA levels between control group and study group after PET

d: Comparison of endocan levels between control group and study group before PET

e: Comparison of endocan levels between control group and the study group after PET

f: Comparison of endocan levels in the study group before and after PET

g: Comparison of NSE levels between control group and the study group before PET

h: Comparison of NSE levels in the study group before and after PET

i: Comparison of NSE levels between control group and the study group before PET 